\title{
Evaluation of foraminal transportation during foraminal enlargement with different instrumentation systems
}

\author{
Diogo Silva ${ }^{1}$, Aline Cristine Gomes ${ }^{1}$, Juliana Melo da Silva ${ }^{2}$, Aline de Almeida Neves ${ }^{3}$, \\ Alexandre Augusto Zaia ${ }^{1}$, Emmanuel João Nogueira Leal da Silva ${ }^{4}$
}

${ }^{1}$ Universidade Estadual de Campinas - UNICAMP, Piracicaba Dental School, Department of Endodontics, Piracicaba, SP, Brazil

3 Universidade Federal do Rio de Janeiro - UFRJ, School of Dentistry, Department of Paediatric Dentistry, Rio de Janeiro, RJ, Brazil

${ }^{4}$ Universidade do Grande Rio - UNIGRANRIO, School of Dentistry, Department of Endodontics, Rio de Janeiro, RJ, Brazil

\begin{abstract}
Aim: To evaluate the foraminal transportation during foraminal enlargement after manual instrumentation with stainless steel files, preparation with the Mtwo system and Reciproc R25 file. Methods: Thirty roots were selected, divided in three groups and prepared in accordance with the different instrumentation systems: Hand Files (HF); Mtwo system (MS); and Reciproc system (RS). All groups were prepared with the instrumentation level $1 \mathrm{~mm}$ beyond the apex. Photomicrographs were performed using scanning electron microscopy, to record the foraminal anatomy before and after instrumentation. Data were analyzed using ANOVA followed by Tukey's test with a significance level of $5 \%$. Results: The group instrumented with hand files showed higher foraminal transportation when compared to the Mtwo and Reciproc groups $(p<0.05)$. Reciproc group showed lower transportation when compared to the Mtwo group $(p<0.05)$. Conclusions: The stainless steel files caused significant foraminal transportation, while Reciproc system showed safe apical preparation, with little transportation.
\end{abstract}

Keywords: endodontics; linstrumentation; anatomy.

\section{Introduction}

The apical limit of root canal instrumentation is still a controversial topic in root canal therapy ${ }^{1-2}$. In cases of apical periodontitis, recognizing the presence of microorganisms not only in the apical portion of the canal, but even within the lesion itself, has contributed to the concept of cleaning, debridement and enlargement of the apical foramen during root canal instrumentation ${ }^{3-4}$. In fact, these procedures can overcome the potential limitation of irrigation procedures in the apical area, optimizing root canal disinfection ${ }^{5-9}$.

One of the main concerns during foraminal enlargement is the possibility of

Received for publication: July 21, 2014 Accepted: November 25, 2014

Correspondence to: Emmanuel João Nogueira Leal da Silva Rua Herotides de Oliveira, 61/902 - Icaraí CEP: 24230230 -Niterói, RJ, Brasil E-mail: nogueiraemmanuel@hotmail.com foraminal transportation, especially when curved canals are prepared ${ }^{10-11}$. When excessive hard tissue is removed in a single direction, some areas may be left unprepared, favoring the presence of remaining necrotic tissue, contaminated dentin chips and microorganisms. Moreover, this foraminal transportation may compromise the apical seal after root canal filling ${ }^{12}$.

The introduction of rotary nickel-titanium (NiTi) files has improved root canal shaping ${ }^{13}$, because of their high flexibility and cutting ability ${ }^{14-15}$, allowing 
greater efficiency and predictability of root canal instrumentation and providing better centering and less apical transportation in the canal compared to hand instrumentation with stainless-steel instruments ${ }^{16-17}$. However, despite their advantages, NiTi rotary instruments may undergo premature failure by flexion and/or torsion ${ }^{18}$. Cyclic fatigue fracture occurs as consequence of the continuous rotation of an instrument in a curved space. In this condition, the instrument under elastic deformation is subjected to a mechanical load represented by alternating tensile and compressive stresses ${ }^{19}$, leading to instrument fracture by low-cycle fatigue mechanism ${ }^{20-21}$. Cyclic fatigue resistance comprises thus the number of cycles that an instrument can endure until fracture under a specific load condition. Because NiTi instruments may show no visible signs of permanent deformation during cyclic fatigue, instrument separation may occur unexpectedly 22

Recently, a new approach was introduced to enlarge the root canal space in which a single NiTi rotary instrument is used using a reciprocating movement ${ }^{23}$. The concept of a single NiTi instrument to prepare the entire root canal up to a minimum taper-size is appealing, since the learning curve is considerably reduced due to an over-simplification of the technique. Moreover, there is no doubt that in a cost-effective perspective, the use of only one NiTi instrument is more advantageous than the conventional multi-file NiTi systems. To some extent, the reciprocation-based systems have brought new perspectives in mechanical root canal preparation. Reciprocating movements somehow mimic the manual instrumentation procedures. Moreover, there is some evidence that it outperforms conventional continuous rotary NiTi preparation ${ }^{24}$. In fact, the first experimental and clinical impression of the single-file reciprocating systems seems promising ${ }^{25-28}$.

However, some important parameters still need be properly assessed; for instance, the effect of reciprocation movement on foramen enlargement. Therefore, the present study was designed to evaluate the foraminal transportation during foraminal enlargement, comparing the conventional sequence of the Mtwo system files with the Reciproc R25 file. Conventional crown-down hand-file instrumentation was used as control. The tested null hypothesis was that there are no differences in foraminal transportation among the different tested instrumentation systems.

\section{Material and methods}

The present research protocol was approved by the Ethics Committee in Research of the Piracicaba Dental School, University of Campinas, Brazil (080/2009).

Thirty freshly extracted human maxillary molars were used in the present study. Disto-vestibular roots were selected and preoperative digital mesio-distal and bucco-lingual radiographs were taken from each root to confirm the canal anatomy. The criteria for tooth selection included: no visible root caries, fractures or cracks, no signs of internal/external resorption, pulp calcification and a completely formed apex.
Determination of root canal curvature was based on the angle of curvature, initiated at the coronal aspect of the apical third of the root using Schneider's method ${ }^{29}$. Curvature angles were measured using an image analysis program (AxioVision 4.5; Carl Zeiss Vision, Hallbergmoos, Germany). Only roots with angles of curvature ranging from $10^{\circ}$ to $20^{\circ}$ (moderate curvatures) were selected. In addition, only root canals with an initial apical size equivalent to a size $10 \mathrm{~K}$-file were included in the present study. Working length (WL) was established by adding $1 \mathrm{~mm}$ to the canal length. After WL measurement, the length of all roots was standardized at 15 $\mathrm{mm}$ to prevent the introduction of confounders, which might contribute to variations in the preparation procedures. The roots were then analyzed under SEM with $3 \mathrm{kV}$, and $\times 50$ magnification (JSM-5600LV, JEOL, Tokyo, Japan) and secondary electron images were obtained. The specimens were mounted on specific metallic stubs to prevent their movement and to allow the evaluation to be made parallel to the long axis of the foramen.

After the initial image, the specimens were matched in terms of anatomic features, such as root length, foramen diameter, and regarding the angle and radius of the root curvature. Then, the matched teeth were randomly distributed to the experimental groups (10 for each group) using a computer algorithm (http://www.random.org). The experimental groups are described below:

Hand-file technique (HF). The coronal and middle third of each canal was prepared using a Gates-Glidden drill sizes 4, 3 and 2 (Dentsply/Maillefer, Ballaigues, Switzerland) up to the beginning of the canal curvature. The apical third was prepared with a Flexofile (Dentsply/Maillefer) size 50, $45,40,35,30$, and 25 at the WL using the balanced force movement technique ${ }^{16}$. Thus, in total, 9 instruments were used for specimens in this group. Irrigation between each instrument was accomplished with $1 \mathrm{~mL} 0.9 \%$ saline solution applied with a syringe and an open-end needle.

Mtwo Preparation (MS). Ten teeth were prepared with Mtwo instruments, used as recommended by the manufacturer. The following sequence was used: 10/.04 file (full WL), 15/.05 (full WL), 20/.06 (full WL) and 25/.06 (full WL). As used for the HF group, the same irrigation protocol was followed.

Reciproc Preparation (RS). Ten teeth were prepared with a Reciproc R25 file (VDW, Munich, Germany). The file was advanced in the root canal until reaching $2 / 3$ of the previously estimated WL and moved in a slow and gentle in-and-out pecking motion with a $3 \mathrm{~mm}$ amplitude limit. After three complete pecking movements, the instrument was removed from the canal and its flutes were cleaned off by insertion into a spoon-box. At this point, the root canal was fluxed with $1 \mathrm{~mL} 0.9 \%$ saline solution. A straight ISO 10 hand file was gently inserted into the canal, following the manufacturer's recommendations, to achieve the full WL. No instrumentation movement was performed with the hand file up to this point. Another instrumentation step was performed with the R25 file in an attempt to reach the full WL, using the same methodology described before. 
After instrumentation, the specimens were mounted again on the metallic stubs and new photomicrographs were taken after instrumentation. A visual attempt was made to place the samples in the same position in order to record standardized images of the root apex. The major foramen was defined as the opening with the largest diameter found at the root apex ${ }^{30}$.

A grid system was used to evaluate the photomicrographs. It consisted of a circle divided into four equal segments, with its radii projecting to intersect the canal surface; the center of the circle was located at the center of the root canal $^{31}$ (Figure 1). Each segment was measured according to a scoring system (Table 1). A single examiner, trained and calibrated for the study, performed blind evaluations of the images. Approximately $10 \%$ of the sample was re-evaluated in order to calculate the intra-examiner reproducibility (Kappa value).

Data were analyzed using Kruskal-Wallis followed by Mann-Whitney tests assuming a significance level of $5 \%$.

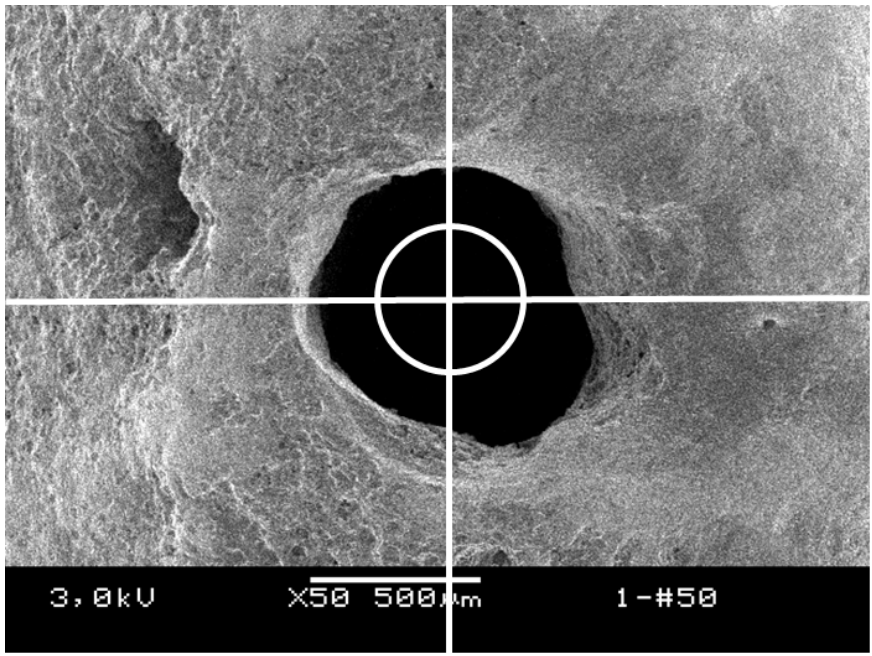

Fig. 1 - Example of the grid system that was used to evaluate foraminal enlargement and deviation.

Table 1 - Scores used for foraminal enlargement analysis and deviation from the original anatomy.

\begin{tabular}{ll}
\hline Score & \multicolumn{1}{c}{ Foraminal Transportation } \\
0 & Apical foramen without deviation from the original anatomy \\
1 & Apical foramen with deviation of a quarter of the circle circumference \\
2 & Apical foramen with deviation of two-quarters of the circle circumference \\
3 & Apical foramen with deviation of three-quarters of the circle circumference
\end{tabular}

\section{Results}

The intra-examiner agreement obtained for the present study was 0.89 according to the Kappa test (substantial agreement).

The median and standard deviation data of foraminal transportation for each experimental group are shown in Table 2. Based on the statistical results, HF group showed higher
Table 2 - Median $( \pm S D)$ of the foraminal transportation scores

\begin{tabular}{lc}
\hline Group & Foraminal trasportation \\
Hand files & $0.91 \pm 1.19^{\mathrm{A}}$ \\
MTwo system & $0.55 \pm 0.80^{\mathrm{B}}$ \\
Reciproc system & $0.20 \pm 0.40^{\mathrm{C}}$
\end{tabular}

Different letters in the same column represent statistically significant differences ( $p$ $<0.05)$.

foraminal transportation than the other tested groups $(p<0.05)$. RS group showed less foraminal transportation than MS group $(\mathrm{p}<0.05)$. Figure 2 shows representative SEM images of the three different tested groups.
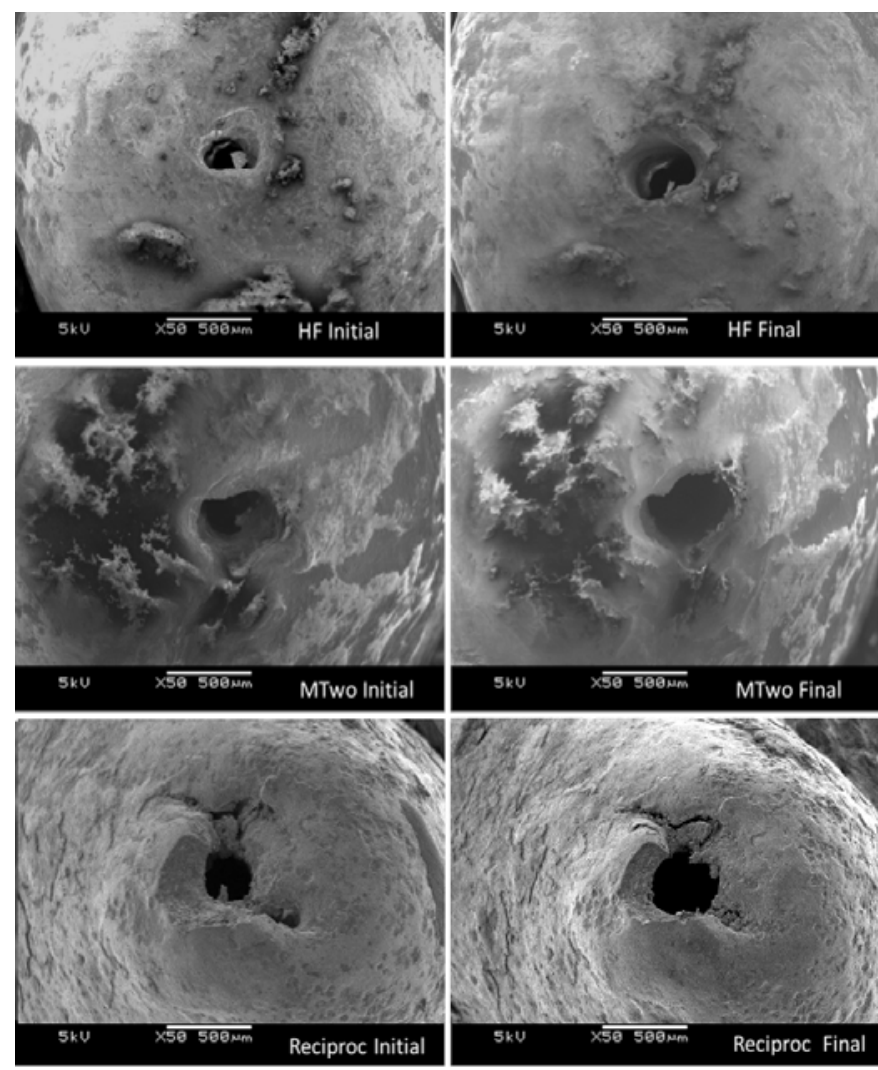

Fig. 2 - SEM micrographs of representative of 3 different groups tested in the study. The figures on the left represent the original image before the instrumentation and the figures on the right side represent the images of the apical foramen after completion of instrumentation.

\section{Discussion}

The apical portion of a root canal is often one of the most difficult locations to achieve adequate cleaning and sanification $^{32-33}$. Moreover, bacteria located in the anatomic complexities such as dentinal tubules, irregularities and ramifications, especially in the apical region, could be protected from the effects of instruments and chemical substances used in the main canal ${ }^{3,34}$. Insufficient cleaning of the apical portion could cause persistent periapical inflammation $^{32}$. An explanation for this is that the used master apical file is frequently too small to achieve sufficient apical 
debridement ${ }^{35}$. It has been reported that increasing the apical foramen diameter may enhance debridement of the apical portion of a root canal ${ }^{36-37}$. In addition, larger apical size preparations have also demonstrated greater microbial reduction in the apical third ${ }^{7,38}$.

The results of the present study showed that foraminal transportations in the RS group were significantly lower than those obtained for the HF and MS groups. Therefore, the null hypothesis was rejected. The advantages of the reciprocation kinematics are somehow based on the balanced force concept ${ }^{39}$. This technique has shown its clinical relevance in maintaining the root curvature with minimum distortion $^{29}$. Furthermore, the reduced cross-sectional metal mass of the instrument, plus the use of the superelastic Mwire alloy provides great flexibility and cutting ability to the Reciproc instrument ${ }^{25}$, which also may justify the current results. Studies have shown that NiTi instruments can cause minor deviations from the main axis of the root canal ${ }^{17}$. Moreover, NiTi instruments have a lower prevalence and severity of root canal transportation when compared with stainless steel instruments ${ }^{17}$.

An important methodological aspect that needs to be addressed in the present study is related to the tooth selection. Despite the high anatomical variability that exists regarding shape, size and dimensions in the natural morphology of teeth, several attempts were made in this study to ensure better comparison of the 3 experimental groups. Special care was taken to obtain groups that were as balanced as possible in terms of anatomic features, such as root length, foramen diameter, and regarding the angle and radius of root curvature. Moreover, as previously suggested matching of teeth was applied when the groups were formed, equalizing levels of challenge and boosting the statistical power of the study ${ }^{24}$.

Although the evaluation of the time spent for preparation of the root canal system with each instrumentation system was not a purpose of this study, it was observed that Reciproc preparation required less time to perform the full instrumentation of the root canal compared with the other groups. These results are in agreement with several previous studies, which demonstrated that instrumentation with reciprocating single file systems can be performed in shorter time $^{23-24,27}$, compared to other instrumentation systems. In spite of requiring less preparation time, some studies have also demonstrated an appropriate effectiveness in cleaning and shaping of the root canals for the Reciproc system ${ }^{27}$. Moreover, this instrumentation system resulted in prepared canals, which maintained the original canal curvature and thus, were extremely safe to use ${ }^{29}$.

Under the conditions of this study, it may be concluded that Reciproc instrumentation was associated with less foraminal transportation compared with hand instrumentation and Mtwo rotary file system.

\section{References}

1. Ricucci D. Apical limit of root canal instrumentation and obturation, part 1. Literature review. Int Endod J.1998; 31: 384-93.
2. Souza RA. The importance of apical patency and cleaning of the apical foramen on root canal preparation. Braz Dent J. 2006; 17: 6-9.

3. Ricucci D, Siqueira JF Jr. Biofilms and apical periodontitis: study of prevalence and association with clinical and histopatological findings. J Endod. 2010; 36: 1277-88.

4. Subramanian K, Mickel AK. Molecular analysis of persistent periradicular lesions and root ends reveals a diverse microbial profile. J Endod. 2009; 35: 950-7.

5. Souza-Filho FJ, Benatti O, Almeida OP. Influence of the enlargement of the apical foramen in periapical repair of contaminated teeth of dog. Oral Surg Oral Med Oral Pathol.1987; 64: 480-4.

6. Albrecht LJ, Baumgartner JC, Marshal JG. Evaluation of apical debris removal using various sizes and tapers of ProFile GT files. J Endod. 2004; 30: 425-8.

7. Card SJ, Sigurdsson A, Orstavik D, Trope M. The effectiveness of increased apical enlargement in reducing intracanal bacteria. J Endod. 2002; 28: 779-83.

8. Fernery VJ, Silva-Sousa YTC, Vane JR, Pécora JD, Versiani MA, Sousa-Neto MD. Histological evaluation of the effectiveness of increased apical enlargement for cleaning the apical third of curved canals. Int Endod J. 2010; 43: 988-94.

9. Lin LM, Rosenberg PA. Repair and regeneration in endodontics. Int Endod J. 2011; 44: 889-906.

10. Duran-Sindreu F, García M, Olivieri JG, Mercadé M, Morelló S, Roig M. A comparison of apical transportation between Flex-Master and Twisted Files rotary instruments. J Endod. 2012; 38: 993-5.

11. González Sánchez JA, Duran-Sindreu F, de Noé S, Mercadé M, Roig M. Centring ability and apical transportation after overinstrumentation with ProTaper Universal and ProFile Vortex instruments. Int Endod J. 2012; 45: 542-51.

12. Wu MK, Fan B, Wesselink PR. Leakage along apical root fillings in curved root canals. Part I: effects of apical transportation on seal of root fillings. J Endod. 2000; 26: 210-6.

13. Bird DC, Chambers D, Peters OA. Usage parameters of nickel-titanium rotary instruments: a survey of endodontists in the United States. J Endod. 2009; 35: 1193-7.

14. Kim HC, Kwak SW, Cheung GS, Ko DH, Chung SM, Lee W. Cyclic fatigue and torsional resistance of two new nickel-titanium instruments used in reciprocation motion: Reciproc versus WaveOne. J Endod. 2012; 38: 541-4.

15. Walia H M, Brantley W A., Gerstein $\mathrm{H}$. An initial investigation of the bending and torsional properties of Nitinol root canal files. J Endod.1988; 14: 346-51.

16. Kum K Y, Spängberg L, Cha BY, Il-Young J, Seung-Jong L, ChanYoung $L$. Shaping ability of three ProFile rotary instrumentation techniques in simulated resin root canals. J Endod. 2000; 26: 719-23.

17. Schafer E, Lohmann D. Efficiency of rotary nickel-titanium FlexMaster instruments compared with stainless steel hand K-Flexofile-Part 2. Cleaning effectiveness and instrumentation results in severely curved root canals of extracted teeth. Int Endod J. 2002; 35: 514-21.

18. Arens FC, Hoen MM, Steiman HR, Dietz GC Jr. Evaluation of singleuse rotary nickel titanium instruments. J Endod. 2003; 29: 664-6.

19. Lopes HP, Elias CN, Vieira VT, Moreira EJ, Marques RV, de Oliveira $\mathrm{JC}$ et al. Effects of electro polishing surface treatment on the cyclic fatigue resistance of BioRace nickel-titanium rotary instruments. J Endod. 2010; 36: 1653-7.

20. Pruett JP, Clement DJ, Carnes DL Jr. Cyclic fatigue testing of nickeltitanium endodonticinstruments. J Endod. 1997; 23: 77-85.

21. Zelada G, Varela P, Martin B, Bahíllo JG, Magán F, Ahn S. The effect of rotational speed and the curvature ofroot canals on the breakage of rotary endodontic instruments. J Endod. 2002; 28: 540-2

22. Sattapan B, Nervo GJ, Palamara JE, Messer HH. Defects in rotary nickel-titanium files after clinical use. J Endod. 2000; 26: 161-5. 
23. Yared G. Canal preparation using only one Ni-Ti rotary instrument: preliminaryobservations. Int Endod J. 2008; 41: 339-44.

24. De-Deus G, Brandão MC, Barino B, Di Giorgi K, Fidel RA, Luna AS. Assessment of apically extruded debris produced by the single-file ProTaper F2 technique under reciprocating movement. Oral Surg Oral Med Oral Pathol Oral Radiol Endod. 2010; 110: 390-4.

25. Varela-Patino P, Ibañez-Párraga A, Rivas-Mundiña B, Cantatore G, Otero $\mathrm{XL}$, Martin-Biedma B. Alternating versus continuous rotation: a comparative study of the effect on instrument life. J Endod. 2010; 36: 157-9.

26. Meireles DA, Bastos MM, Marques AA, Garcia LD, Sponchiado EC Júnior. Endodontic treatment of mandibular molar with root dilaceration using Reciproc single-file system. Restor Dent Endod. 2013; 38: 167-71.

27. Machado ME, Nabeshima CK, Leonardo MF, Reis FA, Britto ML, Cai $\mathrm{S}$. Influence of reciprocating single-file and rotary instrumentation on bacterial reduction on infected root canals. Int Endod J. 2013; 46: 1083-7.

28. Basmaci F, Oztan MD, Kiyan M. Ex vivo evaluation of various instrumentation techniques and irrigants in reducing $\mathrm{E}$. faecalis within root canals. Int Endod J. 2013 ; 46: 823-30.

29. Schneider SW. A comparison of canal preparations in straight and curved root canals. Oral Surg Oral Med Oral Pathol. 1971; 32: 271-5.

30. Martos J, Lubian C, Silveira LF, Suita de Castro LA, Ferrer Luque CM. Morphologic analysis of the root apex in human teeth. J Endod. 2010; 36: 664-7.

31. Tan BT, Messer $\mathrm{HH}$. The effect of instrument type and pre flaring on apical file size determination. Int Endod J. 2002; 35: 752-8.

32. Nair PN, Henry S, Cano V, Vera J. Microbial status of apical root canal system of human mandibular first molars with primary apical periodontitis after "one-visit" endodontic treatment. Oral Surg Oral Med Oral Pathol Oral Radiol Endod. 2005; 99: 231-52.

33. Fornari VJ, Silva-Sousa YT, Vanni JR, Pécora JD, Versiani MA, SousaNeto MD. Histological evaluation of the effectiveness of increased apical enlargement for cleaning the apical third of curved canals. Int Endod J. 2010; 43: 988-94.

34. Nair PN. On the causes of persistent apical periodontitis: a review. Int Endod J. 2006; 39: 249-81.

35. Wu M-K, Roris A, Barkis D, Wesselink PR. Prevalence and extent of long oval shape of canals in the apical third. Oral Surg Oral Med Oral Pathol Oral Radiol Endod. 2000; 89: 739-43.

36. Lee S-J, Wu M-K, Wesselink PR. The efficacy of ultrasonic irrigation to remove artificially placed dentin debris from different sized simulated plastic root canals. Int Endod J. 2004; 37: 607-12.

37. Van der Sluis LWM, Wu M-K, Wesselink PR. The efficacy of ultrasonic irrigation to remove artificially placed dentin debris from human root canals prepared using instruments of varying taper. Int Endod J. 2005; 38: 764-8.

38. Shuping G, Ørstavik D, Sigurdsson A, Trope M. Reduction of intracanal bacteria using nickel-titanium rotary instrumentation and various medications. J Endod. 2000; 26: 751-5.

39. Roane JB. Balanced force and rotary shaping. Compend Contin Educ Dent. 2005; 26: 12-8. 